\title{
26 Research Square \\ Individual variability in the size and organization of the human arcuate nucleus of the medulla
}

Joan Susan Baizer ( $\nabla$ baizer@buffalo.edu )

University at Buffalo https://orcid.org/0000-0003-0692-3765

Sandra F. Witelson

McMaster University Medical Centre

\section{Research Article}

Keywords: human brainstem, pontine nuclei, inferior olive, Sudden Infant Death Syndrome, cerebellum

Posted Date: May 11th, 2021

DOI: https://doi.org/10.21203/rs.3.rs-476922/v1

License: (9) This work is licensed under a Creative Commons Attribution 4.0 International License. Read Full License

Version of Record: A version of this preprint was published at Brain Structure and Function on October 6th, 2021. See the published version at https://doi.org/10.1007/s00429-021-02396-4. 


\section{Abstract}

The arcuate nucleus (Arc) of the medulla is found in almost all human brains and in a small percentage of chimpanzee brains. It is absent in the brains of other mammalian species including mice, rats, cats and macaque monkeys. The Arc is classically considered a precerebellar nucleus, presumably motor in function. However, several studies have found aplasia of the Arc in babies who died of SIDS (Sudden Infant Death Syndrome) suggesting a very different role for the Arc in the control of respiration. Aplasia of the Arc, however, has also been reported in adults suggesting that it is not critical for survival. We have examined the Arc in closely-spaced Nissl-stained sections in human cases to acquire a better understanding of the degree of variability of its size and location in adults. We have also examined immunostained sections to develop a neurochemical profile of this nucleus. Our data suggest that the Arc consists of rostral and caudal subdivisions. There is some degree of left-right asymmetry in Arc position, size and shape at all rostro-caudal levels. Neurons in the Arc express calretinin (CR), neuronal nitric oxide synthase (nNOS) and nonphosphorylated neurofilament protein (NPNFP) but not calbindin (CB) or parvalbumin (PV). There is also immunostaining for GAD and GABA receptors suggesting inhibitory input to Arc neurons. We support the classical idea of the Arc as a precerebellar nucleus; its absence in SIDS cases may not be the cause of death but rather a correlate of other brainstem abnormalities.

\section{Introduction}

The arcuate nucleus of the medulla (Arc) is a prominent structure in the human brainstem (Olszewski and Baxter 1982; Mikhail and Ahmed 1975; Essick 1912). We found a similar structure in a minority of chimpanzee brainstems (Baizer et al. 2013a). However, no such structure has been described in the medulla of many other mammalian species including the mouse (Paxinos and Franklin 2004; Sidman et al. 1971), rat (Paxinos 1999; Paxinos and Watson 1997), and cat (Berman 1968) and rhesus monkey (Paxinos et al. 2000). A brainstem nucleus called the Arc was proposed in mice, but its homology with the human Arc questioned on the grounds of neurochemical differences between the mouse and the human nuclei (Fu and Watson 2012).

Classically, the Arc is considered a precerebellar nucleus, with a role in motor function (Olszewski and Baxter 1982; Rasmussen and Peyton 1946). A totally different view of the Arc has been proposed on the basis of neuropathological observations showing aplasia of the Arc in the brains of children who died of SIDS (Sudden Infant Death Syndrome. Another term for the same syndrome is Sudden Unexpected Death in Infancy, SUDI. A closely related syndrome is Sudden Intrauterine Death Syndrome, SIUDS. We will use the term SIDS to include all cases of sudden unexpected death, both prenatal and postnatal). Such cases are described in many studies (Filiano and Kinney 1992; Kinney et al. 1992; Matturri et al. 2000; Filiano and Kinney 1995, 1994; Kinney and Filiano 1988; Franciosi and Segura 2004; Biondo et al. 2003; Folgering et al. 1979). The interpretation of these observations was that the Arc is the site of chemosensitive neurons that are critical for respiration and therefore survival (Filiano et al. 1990). However, Paradiso et al. (2018) found aplasia and hypoplasia of the Arc in the brains of adults, suggesting that it was not critical for survival. 
There is thus uncertainty about the function of the Arc. It is also clear that there is significant individual variability in the size and position of the Arc in different human brains. This is well-illustrated by its depiction in two atlases of the human brainstem. Olszewski and Baxter (1982) show the Arc as beginning caudal to the obex (plate VIII) and extending rostrally to the pontine nuclei (pn; plate XVIII). Caudally it is a small cell group ventrolateral to the pyramidal tracts (py). More rostrally it is located ventromedially to the py and extends up the midline. By contrast, atlas of Paxinos and Huang (1995) shows the Arc as a small caudal cell group ventrolateral to the py and well caudal to the pontine nuclei (Figs. 19 and 20, Obex +2 and $+3 \mathrm{~mm})$.

Very little is known about transmitters, receptors and patterns of expression of calcium-binding proteins in neurons of the Arc. Such information could be useful in understanding the substrate for information processing in the Arc. We have examined Nissl and immunostained sections of 13 brainstems from the Witelson Normal Brain Collection. The results confirm individual variability in size and shape of the Arc, but show similarity across cases in its neurochemical characteristics. The data also suggest that the Arc may consist of distinct caudal and rostral subdivisions.

\section{Material And Methods}

We studied Nissl and immunostained sections from brainstems from the Witelson Normal Brain Collection (Witelson and McCulloch 1991). Table 1 shows the critical parameters of the cases including age, sex, and post-mortem interval (PMI). Some sections had been prepared for studies of other brainstem structures (Baizer et al. 2018; Baizer 2014; Baizer et al. 2013b; Baizer et al. 2011a; Baizer et al. 2011b; Baizer and Broussard 2010; Baizer et al. 2007). We here include data from several previously unpublished cases. 
Table 1

Cases studied.

\begin{tabular}{|lllll|}
\hline \multicolumn{5}{|c|}{ Witelson Normal Brain Collection } \\
\hline & Case \# & Age & Sex & PMI (hr) \\
\hline 1 & 125 & 57 & $\mathrm{~m}$ & 5 \\
\hline 2 & 150 & 63 & $\mathrm{~m}$ & 3 \\
\hline 3 & 155 & 50 & $\mathrm{f}$ & 9 \\
\hline 4 & 158 & 51 & $\mathrm{~m}$ & 1 \\
\hline 5 & 164 & 45 & $\mathrm{f}$ & 3 \\
\hline 6 & 166 & 65 & $\mathrm{f}$ & 3 \\
\hline 7 & 167 & 55 & $\mathrm{f}$ & 2 \\
\hline 8 & 168 & 69 & $\mathrm{~m}$ & 3 \\
\hline 9 & 169 & 70 & $\mathrm{~m}$ & 2 \\
\hline 10 & 171 & 63 & $\mathrm{f}$ & 6 \\
\hline 11 & 176 & 71 & $\mathrm{f}$ & 3 \\
\hline 12 & 180 & 54 & $\mathrm{~m}$ & 2 \\
\hline 13 & 183 & 69 & $\mathrm{~m}$ & 2 \\
\hline
\end{tabular}

Histological procedures. The details of tissue acquisition were given in Witelson and McCulloch (1991). The brains were stored in 10\% formalin. The brainstems were dissected away from the cerebrum and cerebellum and then cryoprotected in $15 \%$ then $30 \%$ sucrose in $10 \%$ formalin. Prior to sectioning, we made a small slit was made along one side of the ventral brainstem to allow identification of left and right sides of the brain. This slit can be seen in some of the photomicrographs. Forty $\mu \mathrm{m}$ thick frozen sections were cut on an $\mathrm{AO}$ sliding microtome in a plane transverse to the brainstem. All sections were collected and stored in plastic compartment boxes, 5 sections/compartment, at $4^{\circ} \mathrm{C}$ in $5 \%$ formalin. Sets of Sect. $2 \mathrm{~mm}$ apart from each case were stained with a Nissl stain, Cresyl Violet (CV), following a standard protocol (LaBossiere and Glickstein 1976). Additional sections were stained as needed to further define the extent of the Arc.

\section{Antibodies and Immunohistochemistry (IHC).}

Detailed protocols for immunohistochemistry were described in those earlier publications. Briefly, all immunohistochemistry was done on free-floating sections. Sections were first treated with an antigen retrieval (AR) protocol. Sections were rinsed and then nonspecific label was blocked by incubating sections in a solution of phosphate buffered saline (PBS), $1 \%$ Triton-X $100,1 \%$ bovine serum albumin 
and $1.5 \%$ normal serum. Sections were then incubated in that solution with the primary antibody added overnight at $4^{\circ} \mathrm{C}$ on a tissue rocker. Further processing was with the Vector "ABC" method using a Vector Elite kit (Vector Laboratories, Burlingame, CA) and visualization with 3,3'-diaminobenzidine (DAB; Sigma) giving brown staining, or a glucose oxidase modification of that protocol, giving gray-black staining (Shu et al. 1988; Van der Gucht et al. 2006). Sections were mounted on gelled slides, dehydrated in $70 \%, 95 \%$ and $100 \%$ alcohol, cleared in Histosol or Xylene and coverslipped with Permount (Fisher Scientific). Table 2 shows the primary antibodies and dilutions used.

Table 2

Antibodies and dilutions

\begin{tabular}{|c|c|c|c|}
\hline Antigen & Source, Catalogue \# & Host & Dilution \\
\hline Calbindin (CB) & $\begin{array}{l}\text { Chemicon/Millipore } \\
\text { AB1778 }\end{array}$ & $\mathrm{Rb}$ & $1: 2000$ \\
\hline Calretinin (CR) & $\begin{array}{l}\text { Chemicon/Millipore } \\
\text { AB5054 }\end{array}$ & $\mathrm{Rb}$ & $\begin{array}{l}1: 2000- \\
1: 3000\end{array}$ \\
\hline \multirow[t]{2}{*}{$\mathrm{GABA}_{\mathrm{A}}$ Ra1 receptor } & Santa Cruz & \multirow[t]{2}{*}{ Gt } & \multirow[t]{2}{*}{$1: 250$} \\
\hline & sc-31403 & & \\
\hline $\mathrm{GABA}_{\mathrm{B}} \mathrm{R} 1$ receptor & $\begin{array}{l}\text { Chemicon/Millipore } \\
\text { AB2256 }\end{array}$ & GP & 1: 2000 \\
\hline Glutamic acid decarboxylase $\left(\mathrm{GAD}_{65 / 67)}\right.$ & $\begin{array}{l}\text { Chemicon/Millipore } \\
\text { AB1511 }\end{array}$ & $\mathrm{Rb}$ & $1: 1000$ \\
\hline \multirow[t]{2}{*}{ Nitric oxide synthase (nNOS) } & Cayman & \multirow[t]{2}{*}{$\mathrm{Rb}$} & \multirow[t]{2}{*}{$1: 200$} \\
\hline & 160870 & & \\
\hline \multirow{2}{*}{$\begin{array}{l}\text { Nonphosphorylated neurofilament protein } \\
\text { (NPNFP) }\end{array}$} & Covance & \multirow[t]{2}{*}{ Ms } & \multirow[t]{2}{*}{$1: 1000$} \\
\hline & SMI-32 & & \\
\hline \multirow[t]{2}{*}{ Parvalbumin (PV) } & Sigma & \multirow[t]{2}{*}{ Ms } & \multirow[t]{2}{*}{$1: 2000$} \\
\hline & P3088 & & \\
\hline
\end{tabular}

Data Analysis and Photography. Sections were examined with a Leitz Dialux 20 light microscope, and digital images (1600 x 1200 pixels) captured with a SPOT Insight Color Mosaic camera. We used the same camera with a Wild Makroscope for lower-magnification images. Brightness, contrast and color of the images were adjusted and figures assembled with Adobe Photoshop software (San Jose, CA).

Terminology and abbreviations. With a few exceptions we follow the abbreviations for anatomical structures used in the atlas of Paxinos and Huang (1995); we have introduced the new terms cArc and rArc for the caudal and rostral subdivisions of the Arc. Abbreviations are listed in Table 3.

\section{Results}




\section{Size and location of the Arc.}

We analyzed Nissl-stained sections from 13 cases (Table 1). We found an Arc in each case, but variability among cases in the location, size, shape, and degree of left-right asymmetry of the Arc. We tentatively divide the Arc into caudal and rostral subdivisions. The caudal subdivision (cArc) consists of neurons located ventrolaterally to the py whereas the rostral Arc ( $\mathrm{rArc}$ ) is found ventromedially to the py with neurons extending up the midline. In some cases, the neurons and processes of the Arc are not restricted to the surface of the brain but invade the py. We will first illustrate the appearance of the Arc in Nisslstained sections from a single case, and then show examples from other cases illustrating key aspects of the variability. We will then illustrate the neurochemical characteristics of the Arc.

The Arc in Case 158. The Arc in this case has a rostro-caudal extent of about $8 \mathrm{~mm}$. The shape and position of the Arc cell groups in this case were different at caudal and rostral levels, we distinguish cArc and rArc. There is left-right asymmetry in the Arc at all levels. The cArc began at a level caudal to the appearance of the IOpr as a ventrolateral narrow band of neurons (Fig. 1a; arrows). There was some asymmetry between left and right sides, with the band on the left longer than on the right. Figure $1 \mathrm{~b}$ shows a section about $2 \mathrm{~mm}$ rostral to the one in Fig. 1a; the size and position of the Arc are similar, with the band on the left narrower than the band on the right. As illustrated in Fig. 1c, the neurons of the Arc are apparently randomly scattered and of different soma shapes, typically polygonal but including elongated and oval examples. About $2 \mathrm{~mm}$ more rostrally (Fig. 1d), the Arc consists of more compact and more medial groups of neurons (Fig. 1d, arrow shows Arc on the right). This shift in position marks the beginning of the rArc. The development of the midline Arc continues at more rostral levels (Figs. 1e, f, g). In Fig. $1 \mathrm{~g}$ the arrow shows the Arc on the left; it is larger and more complex than on the right. In this case, the neurons of the Arc invade the py (Fig. 1f, g, arrowheads on the right). At the caudal level of the pn, the midline Arc is quite large (Fig. 1k). The images in Fig. $1 \mathrm{~h}$, j show the random scattering of neurons with round, oval, polygonal and elongated somata. Figure 1 l shows that the pn neurons are similar in size, density, and variety of soma shapes.

Variability in cArc and rArc. In Case 158, the cArc consisted of a small cell group ventrolateral to the py (Fig. 1b,c). However, the cArc had other configurations in other cases. Figure 2 shows examples of the cArc in three additional cases. In Case 171 (Fig. 2a,b) the cArc was much larger, a very broad band of neurons interior to the py (Fig. 2a, arrow). The Arc in Case 125 was also larger than in Case 158, a long band (Fig. 2c) but ventrolateral to the py. In Case 176 (Fig. 2e) the cArc was similar to that in Case 158, a small cell group ventrolateral to the py. Despite the major variations in size, the neurons in the Arc in all 3 cases (Fig. 2b,d,f) were similar to those in the first case (Fig. 1c) in sizes, shapes, and density.

There was also variability in the configuration of the Arc at more rostral levels. The rArc consists of neurons that are ventromedial to the py as well as neurons in that extend up along the midline, often in a complex shape (as shown in Fig. 1g,h). In Case 125 (Fig. 3a) the midline neurons formed a rather narrow band (arrow) with an irregularly shaped broader band of neurons ventromedially (Fig. 3a, arrowhead). In Case 155 (Fig. 3c) the midline component was broader (arrow) and more complex and the ventromedial 
band (arrowhead) narrower, with marked asymmetry. In Case 176, the midline structure was even broader (Fig. 3e, arrow) while the ventromedial band (arrowhead) narrower. Again, despite the variability in size of the Arc, its component neurons appeared similar in different cases (Fig. 3b,d,f).

Cases also varied in the geographical relationship between caudal and rostral Arc. In some cases (6/13), as in the case illustrated in Fig. 1, they were continuous; the Arc was not missing on any sections examined. It is of course possible that even more closely spaced sections might show a discontinuity. In other cases (7/13) they were discontinuous, with gaps typically of $1-3 \mathrm{~mm}$ between the end of the cArc and the beginning of the rArc. This discontinuity again supported the idea that cArc and rArc are independent subdivisions.

Neurochemistry. In examining immunostaining sections, we asked if there were individual differences in protein expression (as was found for the inferior olive, Baizer et al. 2011b) or if immunoreactivity to calcium-binding proteins might define subdivisions in the Arc as in vestibular nuclei (Baizer and Broussard 2010). In illustrating these results, we also show more examples of the variability in the configuration of the Arc among cases. We will first describe the expression of proteins in somata of Arc cells, and then the markers for which expression was seen in puncta but not somata, and finally the evidence of GABAergic input to Arc neurons.

CR. Cells in the Arc express the calcium-binding protein CR. Figure 4 illustrates this finding for the rArc in two cases. Comparison of Nissl sections (Fig. 4a,C) with neighboring immunostained sections (Fig. 4b,d) shows about the same numbers of labeled neurons, suggesting that all cells are $\mathrm{CR}^{+}$. The immunolabeled sections also show more details of Arc organization with strands of immunolabeled processes extending outside the regions of labeled somata (Fig. 4d, arrowheads).

nNOS. We found immunolabel of somata throughout the Arc. As with CR, it appeared that every Arc neuron was immunolabeled. Figure 5a,b compare Nissl and nNOS immunostaining in the Arc of Case 158. At the level illustrated there are many Arc neurons ventromedial to the py with a few along the midline. These sections also illustrate the invasion of the py by neurons and processes of the arc (arrows), especially dramatic in the immunolabeled section (Fig. 5b). There is dense immunolabel of somata that are embedded in a region of dense punctate label. The configuration of the midline Arc is shown in Fig. 5c,d. Again, there is label of somata embedded in dense punctate label with strands and islands of immunolabel extending into the py (Fig. $5 \mathrm{c}$, arrows). The higher magnification image shows the dense punctate label and shows densely labeled somata (example at arrow).

NPNFP. The third marker that immunolabeled somata in the Arc was nonphosphorylated neurofilament protein, and the characteristics of the immunostaining were similar across cases. Figure 6a shows the dense immunostaining in patches along the midline in Case 155. The higher magnification image (Fig. 6b) shows immunolabel of somata (example at arrow) embedded in a dense meshwork of immunostained fibers. A similar pattern of very dense immunostaining both along the midline and 
ventromedial to the py is shown for Case 158 (Fig. 6c). Immunostained somata (Fig. 6d, arrows) are embedded in a dense meshwork of immunostained processes.

$\mathrm{CB}$ and PV. While there was immunostaining of somata with the calcium-binding protein $\mathrm{CR}$, the pattern with the two other calcium-binding proteins, $C B$ and PV, was quite different. With an antibody to $C B$, immunostaining clearly distinguished the entire Arc, as shown for two cases in Fig. 7. The Arc is shown in Nissl-stained sections (Fig. 7a,d) and immunostaining in adjacent sections (b, e). However, the immunostaining was not of somata but of puncta distributed throughout the Arc (Fig. 7c,f). Furthermore, in both cases there were regions of lighter and darker (arrows in Fig. 7c,d) immunostaining. For the third calcium-binding protein, PV, there was no immunostaining in the Arc at all. Figure 8 shows this for two cases. The Arc is clearly defined in Nissl stained-sections (Fig. 8a,c) and completely devoid of immunostaining (Fig. 8b,d). There are immunostained fibers in the adjacent py.

GABA as a transmitter in the Arc. Both the connections and the nature of information processing in the Arc are mysterious. We also used antibodies to $G_{A D} D_{65 / 67}$, the synthetic enzyme for $G A B A$ as well as to $\mathrm{GABA}_{A}$ and $G A B A_{B}$ receptors to assess possible GABAergic input to the Arc. Figure 9a show immunostaining for $\mathrm{GAD}_{65 / 67}$, defines the region of the midline and ventromedial Arc in Case 155. Figure $9 \mathrm{~b}$ illustrates the punctate nature of this immunostaining, consistent with GABAergic terminals. Figure $9 \mathrm{c}$ shows that there is immunostaining for $\mathrm{GABA}_{A}$ receptors, again, distributed evenly over the Arc and Fig. $9 d$ shows that both somata and processes are labeled. Figure $9 e, f$ show immunolabel for $G A B A_{B}$ receptors, with label restricted to somata.

\section{Discussion}

We have studied the organization and neurochemical properties of the arcuate nucleus of the medulla in 13 human cases. We have found individual variability in its size and shape but similar neurochemical profiles among cases. We will discuss these results first from a neuroanatomical perspective and then summarize the data concerning a proposed role for the Arc in SIDS.

Organization of the Arc; cArc and rArc. We found cell groups consistent with the description and location of the Arc in all cases we examined, but its relative size and shape varied among cases. In the case that we illustrated in Fig. 1 the Arc was present continuously from a level caudal to the IOpr all the way to the pontine nuclei. In other cases, however, there was a discontinuity between caudal and rostral subdivisions of a range typically from 1 to $3 \mathrm{~mm}$. The Arc in the atlas of Olszewski and Baxter (1982) was discontinuous, with the cArc shown on plates VIII and X, absent on plate XII and the rArc beginning on plate XIV. In the atlas of Paxinos and Huang (1995) only the cArc was shown. This discontinuity leads to the suggestion that the Arc should be considered as two subdivisions, the caudal subdivision in which neurons are ventrolateral and the rostral subdivision in which neurons are found ventromedially and also continue dorsally along the midline. The overall appearance of constituent neurons is the same in cArc and rArc. It is unknown if there are different afferents to or efferents from cArc and rArc, and it is also unknown if there might be associated functional differences. We also saw variability among cases in the 
extent to which neurons and processes of the Arc invaded the py. Invasion of the py by Arc neurons was described by Mikhail and Ahmed (1975).

\section{Variability and asymmetry of the Arc and IOpr}

We have shown individual variability in the size, shape and location of the Arc, consistent with early observations (Essick 1912; Rasmussen and Peyton 1946). Variability is however, not unique for a human brainstem structure. We have shown variability in two other brainstem nuclei, the principal nucleus of the inferior olive (IOpr) and nucleus paramedianus dorsalis (PMD). For the IOpr, different cases differed in rostro-caudal extent of the nucleus, in folding pattern of the IOpr ribbon, and in neurochemical properties (Baizer et al. 2011b; Baizer et al. 2018). We saw no cases in which the IOpr was dramatically bigger or smaller than typical, or missing altogether. We also saw individual variability in the size of another brainstem nucleus, the PMD (Baizer et al. 2007). Individual variability in cortical sulcal and gyral patterns is well-established, and has clear functional correlates (Régis et al. 2005; Fedeli et al. 2020; Bonte et al. 2013; Glasel et al. 2011). Our data clearly show that there is variability in brainstem structures in humans as well, but the functional correlates are so far unknown.

Both the IOpr and the Arc show left-right asymmetry in individual cases, both in humans and chimpanzees (Baizer et al. 2013a; Baizer et al. 2011b). Asymmetry has been extensively documented in cerebral cortex, and anatomical asymmetry has associated with functional asymmetry, especially for handedness and language (LeMay 1976; Amunts et al. 1999; Toga and Thompson 2003; Volkmann et al. 1998; Geschwind and Levitsky 1968; Gilles and Gomez 2005; Dorsaint-Pierre et al. 2006; Ochiai et al. 2004). We do not know the functional significance of brainstem asymmetries. Our hypothesis for the IOpr was that differences in size or folding pattern might be related to handedness; our data did not support that idea (Baizer et al. 2011b). Asymmetry in brainstem structures could be the result of as yet not understood developmental processes, or a correlate of asymmetries in cortical development (Gilles and Gomez 2005; Naidich et al. 1994). In general, the brains of other species including mice, rats, and cats do not show marked asymmetry of brainstem structures (Berman 1968; Paxinos and Watson 1997; Paxinos and Franklin 2004; Sidman et al. 1971).

Neurochemical characteristics of the Arc. Somata of Arc neurons expressed CR, nNOS, and NPNFP and not CB. Expression of CR in Arc neurons was also reported by Stonebridge et al. (2020). These data show again that the neurochemical profile of the Arc is different from that in the 10 in the absence of immunostaining for $C B$ in Arc somata. CR is expressed in somata of both structures (Baizer et al. 2011b; Stonebridge et al. 2020). Expression of CB and CR in IO neurons has also been seen in other species (Yu et al. 2014; Celio 1990). There was immunolabel for NPNFP in neurons and processes of the Arc. In other areas of the brain, notably the cerebral cortex, NPNFP is expressed in neurons with long axons (Hof et al. 1990; Hof and Morrison 1990; Bussiere et al. 2003; Hof et al. 1997). Its presence in the Arc is consistent with long-distance projections to cerebellum. 
Information processing in the Arc. The paper of Mikhail and Ahmed (1975) stated that "it is believed that the nucleus receives "different impulses" by way of collaterals of the corticospinal tract. These observations suggest that the Arc is a simple relay nucleus, receiving signals from cortex and sending efferents to the cerebellum. This would be a similar pattern of connections as seen for pontine nuclei (Gibson et al. 1977; Glickstein et al. 1985; Glickstein et al. 1972; Robinson et al. 1984; Bjaalie 1986; Brodal 1978b, a; Bjaalie and Brodal 1997; Bjaalie et al. 1997; Brodal 1968a, b, c; Brodal and Bjaalie 1997, 1992; Ramnani et al. 2006).

However, the data from immunolabel with GABA-related antibodies suggest that there is also inhibitory input to the Arc, suggesting more complex information processing. The data are also consistent with the idea that there may be intermingling of neurons with different inputs and outputs since the punctate label for GAD and GABA receptors is not uniform. The source of the GABAergic input is not known.

The Arc and the RTN: Respiration. There are many studies reporting aplasia or hypoplasia of the Arc in children who died of SIDS (Filiano and Kinney 1994, 1992, 1995; Kinney 2009; Kinney and Filiano 1988; Kinney et al. 1992; Franciosi and Segura 2004; Matturri et al. 2003; Matturri et al. 2002; Matturri et al. 2004). The Arc has also been implicated in apnea with Multiple System Atrophy (Benarroch et al. 2007). These data have been interpreted as showing that the Arc is the site of chemosensory neurons and hence critical for survival. One caution about these studies concerns how many sections were evaluated. Since the Arc is variable among cases and can be discontinuous, examination of closely spaced sections is needed to confirm/deny its presence. It is possible it was small rather than absent in some of the neuropathological cases. A much more important point, however is the reevaluation of the role of the Arc in respiration. The initial view of the Arc as the locus of chemosensitive neurons critical for respiration was proposed on the general similarity in microscopic appearance of Arc neurons to putative chemosensitive neurons in the ventral medulla of the cat (Filiano et al. 1990). However, since that hypothesis, the localization of the chemosensitive cells critical for respiration has been refined. Such cells are found in a nucleus called the retrotrapezoid nucleus (RTN; Akilesh et al. 1997; Cream et al. 2002; Fernandes-Junior et al. 2020; Guyenet et al. 2019; Holloway et al. 2015; Bodineau et al. 2000; Burke et al. 2015; Bourgeois et al. 2019). Neurons in RTN express the transcription factor Phox2b (Stornetta et al. 2006; Kanbar et al. 2010; Onimaru et al. 2009; Kang et al. 2007; Wang et al. 2013; Wang et al. 2014). The discovery of this marker has allowed the localization of the RTN in multiple species including humans (Levy et al. 2019; Lavezzi et al. 2012; Rudzinski and Kapur 2010). The RTN in humans is well rostral and dorsal to the Arc (Rudzinski and Kapur 2010; Lavezzi et al. 2012). These data suggest that the aplasia of the Arc is not the critical factor in SIDS. This interpretation is consistent with the reports that the human Arc is small or absent in a set of adult human cases (Paradiso et al. 2018). Further, a number of studies have found other CNS abnormalities in SIDS, (Ambrose et al. 2019; Jaster et al. 2008; Kinney et al. 2003; Lavezzi et al. 2012; Lavezzi et al. 2019; Ambrose et al. 2018; Machaalani and Waters 2014; Paine et al. 2014). The aplasia or hypoplasia of the Arc in neuropathological reports may correlate with other brainstem deficits that are more directly responsible for death. While the reevaluation of the role of the Arc in respiration has been recognized in some studies (Presti et al. 2014) the idea still persists in others 
(Stonebridge et al. 2020). Understanding the mechanisms of SIDS depends on accurate identification of the critical brainstem structures.

We would argue that the Arc should be considered a precerebellar nucleus. Olszewski and Baxter (1982) proposed that the Arc neurons were caudally displaced pontine neurons. The neurons of the Arc are similar in size, shape and density to the neurons of the pontine nuclei (Fig. 1C,H,J, L), consistent with that suggestion. However, embryological analysis found that the Arc neurons arise earlier in development than do the pontine neurons Essick (1912), suggesting that they are separate anatomical and functional entities. Presumably, projections from the Arc to the cerebellum are another source of mossy fibers. However, there are many remaining questions about the details of the connections and information processing in the Arc, and why it is present in only a restricted set of species. Answering these questions poses a particular challenge since the Arc is not present in species in which anatomical and electrophysiological experiments designed to understand connections and information processing are possible.

\section{Declarations}

Funding. Funded in part by the Department of Physiology and Biophysics, University at Buffalo.

Conflict of interest/Competing interests. None.

Availability of data and material. All slides for the photomicrographs shown in the paper are available in the laboratory of Dr. Baizer.

Code Availability. Not applicable.

Authors' Contributions. JSB designed the study, stained sections, analyzed results and wrote the manuscript. SFW founded the Witelson Normal Brain Collection and made tissue and records available for this study.

Ethics approval. None required.

\section{References}

Akilesh MR, Kamper M, Li A, Nattie EE (1997) Effects of unilateral lesions of retrotrapezoid nucleus on breathing in awake rats. J Appl Physiol (1985) 82 (2):469-479. doi:10.1152/jappl.1997.82.2.469

Ambrose N, Rodriguez M, Waters KA, Machaalani R (2019) Cell death in the human infant central nervous system and in sudden infant death syndrome (SIDS). Apoptosis 24 (1-2):46-61. doi:10.1007/s10495-0181509-0

Ambrose N, Waters KA, Rodriguez ML, Bailey K, Machaalani R (2018) Neuronal apoptosis in the brainstem medulla of sudden unexpected death in infancy (SUDI), and the importance of standardized 
SUDI classification. Forensic Sci Med Pathol 14 (1):42-56. doi:10.1007/s12024-018-9954-1

Amunts K, Schleicher A, Burgel U, Mohlberg H, Uylings HB, Zilles K (1999) Broca's region revisited: cytoarchitecture and intersubject variability. J Comp Neurol 412 (2):319-341. doi:10.1002/(sici)10969861(19990920)412:2<319::aid-cne10>3.0.co;2-7

Baizer JS (2014) Unique features of the human brainstem and cerebellum. Front Hum Neurosci 8:202. doi:10.3389/fnhum.2014.00202

Baizer JS, Baker JF, Haas K, Lima R (2007) Neurochemical organization of the nucleus paramedianus dorsalis in the human. Brain Res 1176:45-52. doi:S0006-8993(07)01855-0 [pii]

10.1016/j.brainres.2007.08.017

Baizer JS, Broussard DM (2010) Expression of calcium-binding proteins and nNOS in the human vestibular and precerebellar brainstem. J Comp Neurol 518 (6):872-895. doi:10.1002/cne.22250

Baizer JS, Paolone NA, Sherwood CC, Hof PR (2013a) Neurochemical organization of the vestibular brainstem in the common chimpanzee (Pan troglodytes). Brain Struct Funct 218 (6):1463-1485. doi:10.1007/s00429-012-0470-x

Baizer JS, Paolone NA, Witelson SF (2011a) Nonphosphorylated neurofilament protein is expressed by scattered neurons in the human vestibular brainstem. Brain Res 1382:45-56.

doi:10.1016/j.brainres.2011.01.079

Baizer JS, Sherwood CC, Hof PR, Witelson SF, Sultan F (2011b) Neurochemical and structural organization of the principal nucleus of the inferior olive in the human. Anat Rec (Hoboken) 294 (7):11981216. doi:10.1002/ar.21400

Baizer JS, Weinstock N, Witelson SF, Sherwood CC, Hof PR (2013b) The nucleus pararaphales in the human, chimpanzee, and macaque monkey. Brain Struct Funct 218 (2):389-403. doi:10.1007/s00429012-0403-8

Baizer JS, Wong KM, Sherwood CC, Hof PR, Witelson SF (2018) Individual variability in the structural properties of neurons in the human inferior olive. Brain Struct Funct 223 (4):1667-1681.

doi:10.1007/s00429-017-1580-2

Benarroch EE, Schmeichel AM, Low PA, Parisi JE (2007) Depletion of putative chemosensitive respiratory neurons in the ventral medullary surface in multiple system atrophy. Brain 130 (Pt 2):469-475. doi:10.1093/brain/awl357

Berman A (1968) The brain stem of the cat. University of Wisconsin Press, Madison, Wisconsin 
Biondo B, Lavezzi A, Tosi D, Turconi P, Matturri L (2003) Delayed neuronal maturation of the medullary arcuate nucleus in sudden infant death syndrome. Acta Neuropathol 106 (6):545-551.

doi:10.1007/s00401-003-0757-3

Bjaalie JG (1986) Distribution of corticopontine neurons in visual areas of the middle suprasylvian sulcus: quantitative studies in the cat. Neuroscience 18 (4):1013-1033. doi:10.1016/03064522(86)90114-4

Bjaalie JG, Brodal P (1997) Cat pontocerebellar network: numerical capacity and axonal collateral branching of neurones in the pontine nuclei projecting to individual parafloccular folia. Neurosci Res 27 (3):199-210. doi:10.1016/s0168-0102(96)01149-2

Bjaalie JG, Sudbo J, Brodal P (1997) Corticopontine terminal fibres form small scale clusters and large scale lamellae in the cat. Neuroreport 8 (7):1651-1655. doi:10.1097/00001756-199705060-00019

Bodineau L, Frugiere A, Marlot D, Wallois F (2000) Connections between retrotrapezoid nucleus and nucleus tractus solitarii in cat. Neurosci Lett 280 (2):111-114. doi:10.1016/s0304-3940(00)00770-9

Bonte M, Frost MA, Rutten S, Ley A, Formisano E, Goebel R (2013) Development from childhood to adulthood increases morphological and functional inter-individual variability in the right superior temporal cortex. Neuroimage 83:739-750. doi:10.1016/j.neuroimage.2013.07.017

Bourgeois T, Ringot M, Ramanantsoa N, Matrot B, Dauger S, Delclaux C, Gallego J (2019) Breathing under Anesthesia: A Key Role for the Retrotrapezoid Nucleus Revealed by Conditional Phox2b Mutant Mice. Anesthesiology 130 (6):995-1006. doi:10.1097/ALN.0000000000002675

Brodal P (1968a) The corticopontine projection in the cat. Demonstration of a somatotopically organized projection from the second somatosensory cortex. Arch Ital Biol 106 (4):310-312

Brodal P (1968b) The corticopontine projection in the cat. I. Demonstration of a somatotopically organized projection from the primary sensorimotor cortex. Exp Brain Res 5 (3):210-234

Brodal P (1968c) Demonstration of a somatotopically organized projection from the primary sensorimotor cortex to the pontine nuclei in the cat. Folia Morphol (Praha) 16 (2):105-107

Brodal P (1978a) The corticopontine projection in the rhesus monkey. Origin and principles of organization. Brain 101 (2):251-283. doi:10.1093/brain/101.2.251

Brodal P (1978b) Principles of organization of the monkey corticopontine projection. Brain Res 148 (1):214-218. doi:10.1016/0006-8993(78)90392-x

Brodal P, Bjaalie JG (1992) Organization of the pontine nuclei. Neurosci Res 13 (2):83-118. doi:10.1016/0168-0102(92)90092-q 
Brodal P, Bjaalie JG (1997) Salient anatomic features of the cortico-ponto-cerebellar pathway. Prog Brain Res 114:227-249. doi:10.1016/s0079-6123(08)63367-1

Burke PG, Kanbar R, Basting TM, Hodges WM, Viar KE, Stornetta RL, Guyenet PG (2015) State-dependent control of breathing by the retrotrapezoid nucleus. J Physiol 593 (13):2909-2926. doi:10.1113/JP270053

Bussiere T, Giannakopoulos P, Bouras C, Perl DP, Morrison JH, Hof PR (2003) Progressive degeneration of nonphosphorylated neurofilament protein-enriched pyramidal neurons predicts cognitive impairment in Alzheimer's disease: stereologic analysis of prefrontal cortex area 9. J Comp Neurol 463 (3):281-302. doi:10.1002/cne. 10760

Celio MR (1990) Calbindin D-28k and parvalbumin in the rat nervous system. Neuroscience 35 (2):375475. doi:10.1016/0306-4522(90)90091-h

Cream C, Li A, Nattie E (2002) The retrotrapezoid nucleus (RTN): local cytoarchitecture and afferent connections. Respir Physiol Neurobiol 130 (2):121-137. doi:10.1016/s0034-5687(01)00338-3

Dorsaint-Pierre R, Penhune VB, Watkins KE, Neelin P, Lerch JP, Bouffard M, Zatorre RJ (2006) Asymmetries of the planum temporale and Heschl's gyrus: relationship to language lateralization. Brain $129(\mathrm{Pt}$ 5):1164-1176. doi:10.1093/brain/awl055

Essick CR (1912) The development of the nuclei pontis and the nucleus arcuatus in man American Journal of Anatomy 13:25-54

Fedeli D, Del Maschio N, Caprioglio C, Sulpizio S, Abutalebi J (2020) Sulcal Pattern Variability and Dorsal Anterior Cingulate Cortex Functional Connectivity Across Adult Age. Brain Connect 10 (6):267-278. doi:10.1089/brain.2020.0751

Fernandes-Junior SA, Oliveira LM, Czeisler CM, Mo X, Roy S, Somogyi A, Zhang L, Moreira TS, Otero JJ, Takakura AC (2020) Stimulation of retrotrapezoid nucleus Phox2b-expressing neurons rescues breathing dysfunction in an experimental Parkinson's disease rat model. Brain Pathol 30 (5):926-944. doi:10.1111/bpa.12868

Filiano JJ, Choi JC, Kinney HC (1990) Candidate cell populations for respiratory chemosensitive fields in the human infant medulla. J Comp Neurol 293 (3):448-465. doi:10.1002/cne.902930308

Filiano JJ, Kinney HC (1992) Arcuate nucleus hypoplasia in the sudden infant death syndrome. J Neuropathol Exp Neurol 51 (4):394-403. doi:10.1097/00005072-199207000-00002

Filiano JJ, Kinney HC (1994) A perspective on neuropathologic findings in victims of the sudden infant death syndrome: the triple-risk model. Biol Neonate 65 (3-4):194-197. doi:10.1159/000244052

Filiano JJ, Kinney HC (1995) Sudden infant death syndrome and brainstem research. Pediatr Ann 24 (7):379-383. doi:10.3928/0090-4481-19950701-10 
Folgering H, Kuyper F, Kille JF (1979) Primary alveolar hypoventilation (Ondine's curse syndrome) in an infant without external arcuate nucleus. Case report. Bull Eur Physiopathol Respir 15 (4):659-665

Franciosi RA, Segura AD (2004) Sudden and unexpected fetal death associated with agenesis of the arcuate nucleus in the medulla oblongata. Am J Perinatol 21 (7):421-424. doi:10.1055/s-2004-835313

Fu YH, Watson C (2012) The arcuate nucleus of the C57BL/6J mouse hindbrain is a displaced part of the inferior olive. Brain Behav Evol 79 (3):191-204. doi:10.1159/000335032

Geschwind N, Levitsky W (1968) Human brain: left-right asymmetries in temporal speech region. Science 161 (3837):186-187. doi:10.1126/science.161.3837.186

Gibson A, Glickstein M, Stein JF (1977) The projection from visual pontine nucleus neurones to the cerebellum in cats [proceedings]. J Physiol 272 (1):88P

Gilles FH, Gomez IG (2005) Developmental neuropathology of the second half of gestation. Early Hum Dev 81 (3):245-253. doi:10.1016/j.earlhumdev.2005.01.005

Glasel H, Leroy F, Dubois J, Hertz-Pannier L, Mangin JF, Dehaene-Lambertz G (2011) A robust cerebral asymmetry in the infant brain: the rightward superior temporal sulcus. Neuroimage 58 (3):716-723. doi:10.1016/j.neuroimage.2011.06.016

Glickstein M, May JG, 3rd, Mercier BE (1985) Corticopontine projection in the macaque: the distribution of labelled cortical cells after large injections of horseradish peroxidase in the pontine nuclei. J Comp Neurol 235 (3):343-359. doi:10.1002/cne.902350306

Glickstein M, Stein J, King RA (1972) Visual input to the pontine nuclei. Science 178 (4065):1110-1111. doi:10.1126/science.178.4065.1110

Guyenet PG, Stornetta RL, Souza G, Abbott SBG, Shi Y, Bayliss DA (2019) The Retrotrapezoid Nucleus: Central Chemoreceptor and Regulator of Breathing Automaticity. Trends Neurosci 42 (11):807-824. doi:10.1016/j.tins.2019.09.002

Hof PR, Cox K, Morrison JH (1990) Quantitative analysis of a vulnerable subset of pyramidal neurons in Alzheimer's disease: I. Superior frontal and inferior temporal cortex. J Comp Neurol 301 (1):44-54. doi:10.1002/cne.903010105

Hof PR, Morrison JH (1990) Quantitative analysis of a vulnerable subset of pyramidal neurons in Alzheimer's disease: II. Primary and secondary visual cortex. J Comp Neurol 301 (1):55-64. doi:10.1002/cne.903010106

Hof PR, Ungerleider LG, Adams MM, Webster MJ, Gattass R, Blumberg DM, Morrison JH (1997) Callosally projecting neurons in the macaque monkey V1/V2 border are enriched in nonphosphorylated neurofilament protein. Vis Neurosci 14 (5):981-987. doi:10.1017/s0952523800011688 
Holloway BB, Viar KE, Stornetta RL, Guyenet PG (2015) The retrotrapezoid nucleus stimulates breathing by releasing glutamate in adult conscious mice. Eur J Neurosci 42 (6):2271-2282. doi:10.1111/ejn.12996

Jaster JH, Ottaviani G, Matturri L, Lavezzi AM, Zamecnik J, Smith TW (2008) Sudden unexpected death related to medullary brain lesions. Am J Forensic Med Pathol 29 (4):371-374.

doi:10.1097/PAF.0b013e3181847dfc

Kanbar R, Stornetta RL, Cash DR, Lewis SJ, Guyenet PG (2010) Photostimulation of Phox2b medullary neurons activates cardiorespiratory function in conscious rats. Am J Respir Crit Care Med 182 (9):11841194. doi:10.1164/rccm.201001-00470C

Kang BJ, Chang DA, Mackay DD, West GH, Moreira TS, Takakura AC, Gwilt JM, Guyenet PG, Stornetta RL (2007) Central nervous system distribution of the transcription factor Phox $2 b$ in the adult rat. J Comp Neurol 503 (5):627-641. doi:10.1002/cne.21409

Kinney HC (2009) Brainstem mechanisms underlying the sudden infant death syndrome: evidence from human pathologic studies. Dev Psychobiol 51 (3):223-233. doi:10.1002/dev.20367

Kinney HC, Filiano JJ (1988) Brainstem research in sudden infant death syndrome. Pediatrician 15 (4):240-250

Kinney HC, Filiano JJ, Harper RM (1992) The neuropathology of the sudden infant death syndrome. A review. J Neuropathol Exp Neurol 51 (2):115-126. doi:10.1097/00005072-199203000-00001

Kinney HC, Randall LL, Sleeper LA, Willinger M, Belliveau RA, Zec N, Rava LA, Dominici L, lyasu S, Randall B, Habbe D, Wilson H, Mandell F, McClain M, Welty TK (2003) Serotonergic brainstem abnormalities in Northern Plains Indians with the sudden infant death syndrome. J Neuropathol Exp Neurol 62 (11):11781191. doi:10.1093/jnen/62.11.1178

LaBossiere E, Glickstein M (1976) Histological processing for the neural sciences. Charles C. Thomas, Springfield, Illinois

Lavezzi AM, Ferrero S, Paradiso B, Chamitava L, Piscioli F, Pusiol T (2019) Neuropathology of Early Sudden Infant Death Syndrome-Hypoplasia of the Pontine Kolliker-Fuse Nucleus: A Possible Marker of Unexpected Collapse during Skin-to-Skin Care. Am J Perinatol 36 (5):460-471. doi:10.1055/s-00381669398

Lavezzi AM, Weese-Mayer DE, Yu MY, Jennings LJ, Corna MF, Casale V, Oneda R, Matturri L (2012) Developmental alterations of the respiratory human retrotrapezoid nucleus in sudden unexplained fetal and infant death. Auton Neurosci 170 (1-2):12-19. doi:10.1016/j.autneu.2012.06.005

LeMay M (1976) Morphological cerebral asymmetries of modern man, fossil man, and nonhuman primate. Ann N Y Acad Sci 280:349-366. doi:10.1111/j.1749-6632.1976.tb25499.x 
Levy J, Facchinetti P, Jan C, Achour M, Bouvier C, Brunet JF, Delzescaux T, Giuliano F (2019)

Tridimensional mapping of Phox $2 \mathrm{~b}$ expressing neurons in the brainstem of adult Macaca fascicularis and identification of the retrotrapezoid nucleus. J Comp Neurol 527 (17):2875-2884.

doi:10.1002/cne.24713

Machaalani R, Waters KA (2014) Neurochemical abnormalities in the brainstem of the Sudden Infant Death Syndrome (SIDS). Paediatr Respir Rev 15 (4):293-300. doi:10.1016/j.prrv.2014.09.008

Matturri L, Biondo B, Mercurio P, Rossi L (2000) Severe hypoplasia of medullary arcuate nucleus: quantitative analysis in sudden infant death syndrome. Acta Neuropathol 99 (4):371-375. doi:10.1007/s004010051138

Matturri L, Lavezzi AM, Minoli I, Ottaviani G, Rubino B, Cappellini A, Rossi L (2003) Association between pulmonary hypoplasia and hypoplasia of arcuate nucleus in stillbirth. J Perinatol 23 (4):328-332. doi:10.1038/sj.jp.7210900

Matturri L, Minoli I, Lavezzi AM, Cappellini A, Ramos S, Rossi L (2002) Hypoplasia of medullary arcuate nucleus in unexpected late fetal death (stillborn infants): a pathologic study. Pediatrics 109 (3):E43. doi:10.1542/peds.109.3.e43

Matturri L, Ottaviani G, Alfonsi G, Crippa M, Rossi L, Lavezzi AM (2004) Study of the brainstem, particularly the arcuate nucleus, in sudden infant death syndrome (SIDS) and sudden intrauterine unexplained death (SIUD). Am J Forensic Med Pathol 25 (1):44-48.

doi:10.1097/01.paf.0000113813.83779.21

Mikhail Y, Ahmed YY (1975) Outline of the arcuate nucleus in the human medulla oblongata. Acta Anat (Basel) 92 (2):285-291. doi:10.1159/000144447

Naidich TP, Grant JL, Altman N, Zimmerman RA, Birchansky SB, Braffman B, Daniel JL (1994) The developing cerebral surface. Preliminary report on the patterns of sulcal and gyral maturation--anatomy, ultrasound, and magnetic resonance imaging. Neuroimaging Clin N Am 4 (2):201-240

Ochiai T, Grimault S, Scavarda D, Roch G, Hori T, Riviere D, Mangin JF, Regis J (2004) Sulcal pattern and morphology of the superior temporal sulcus. Neuroimage 22 (2):706-719.

doi:10.1016/j.neuroimage.2004.01.023

Olszewski J, Baxter D (1982) Cytoarchitecture of the human brain stem. Second edn. Karger, Basel

Onimaru H, lkeda K, Kawakami K (2009) Phox2b, RTN/pFRG neurons and respiratory rhythmogenesis. Respir Physiol Neurobiol 168 (1-2):13-18. doi:10.1016/j.resp.2009.03.007

Paine SM, Jacques TS, Sebire NJ (2014) Review: Neuropathological features of unexplained sudden unexpected death in infancy: current evidence and controversies. Neuropathol Appl Neurobiol 40 (4):364384. doi:10.1111/nan. 12095 
Paradiso B, Ferrero S, Thiene G, Lavezzi AM (2018) Variability of the medullary arcuate nucleus in humans. Brain Behav 8 (11):e01133. doi:10.1002/brb3.1133

Paxinos G (1999) Chemoarchitectonic atlas of the rat brainstem. Academic Press, San Diego

Paxinos G, Franklin KBJ (2004) The mouse brain in stereotaxic coordinates. Compact 2nd edn. Elsevier Academic Press, Amsterdam; Boston

Paxinos G, Huang XF (1995) Atlas of the human brainstem. Academic Press, San Diego

Paxinos G, Huang XF, Toga AW (2000) The rhesus monkey brain in stereotaxic coordinates. Academic Press, San Diego, Calif.

Paxinos G, Watson C (1997) The rat brain, in stereotaxic coordinates. Compact 3rd edn. Academic Press, San Diego

Presti MF, Schmeichel AM, Low PA, Parisi JE, Benarroch EE (2014) Degeneration of brainstem respiratory neurons in dementia with Lewy bodies. Sleep 37 (2):373-378. doi:10.5665/sleep.3418

Ramnani N, Behrens TE, Johansen-Berg H, Richter MC, Pinsk MA, Andersson JL, Rudebeck P, Ciccarelli O, Richter W, Thompson AJ, Gross CG, Robson MD, Kastner S, Matthews PM (2006) The evolution of prefrontal inputs to the cortico-pontine system: diffusion imaging evidence from Macaque monkeys and humans. Cereb Cortex 16 (6):811-818. doi:10.1093/cercor/bhj024

Rasmussen AT, Peyton WT (1946) Origin of the ventral external arcuate fibers and their continuity with the striae medullares of the fourth ventricle of man. J Comp Neurol 84:325-337. doi:10.1002/cne.900840303

Régis J, Mangin JF, Ochiai T, Frouin V, Riviere D, Cachia A, Tamura M, Samson Y (2005) "Sulcal root" generic model: a hypothesis to overcome the variability of the human cortex folding patterns. Neurol Med Chir (Tokyo) 45 (1):1-17. doi:10.2176/nmc.45.1

Robinson FR, Cohen JL, May J, Sestokas AK, Glickstein M (1984) Cerebellar targets of visual pontine cells in the cat. J Comp Neurol 223 (4):471-482. doi:10.1002/cne.902230402

Rudzinski E, Kapur RP (2010) PHOX2B immunolocalization of the candidate human retrotrapezoid nucleus. Pediatr Dev Pathol 13 (4):291-299. doi:10.2350/09-07-0682-0A.1

Shu SY, Ju G, Fan LZ (1988) The glucose oxidase-DAB-nickel method in peroxidase histochemistry of the nervous system. Neurosci Lett 85 (2):169-171

Sidman RL, Angevine JB, Pierce ET (1971) Atlas of the mouse brain and spinal cord. Harvard University Press, Cambridge, Mass.,

Stonebridge R, Taliano RJ, Velilla TD, Anthony DC (2020) Hypertrophy of the Anterior External Arcuate Fasciculus: A Rare Variant With Implications for the Development of the Arcuate Nucleus. Front 
Stornetta RL, Moreira TS, Takakura AC, Kang BJ, Chang DA, West GH, Brunet JF, Mulkey DK, Bayliss DA, Guyenet PG (2006) Expression of Phox2b by brainstem neurons involved in chemosensory integration in the adult rat. J Neurosci 26 (40):10305-10314. doi:10.1523/JNEUROSCI.2917-06.2006

Toga AW, Thompson PM (2003) Mapping brain asymmetry. Nat Rev Neurosci 4 (1):37-48. doi:10.1038/nrn1009

Van der Gucht E, Youakim M, Arckens L, Hof PR, Baizer JS (2006) Variations in the structure of the prelunate gyrus in Old World monkeys. Anat Rec A Discov Mol Cell Evol Biol 288 (7):753-775. doi:10.1002/ar.a.20350

Volkmann J, Schnitzler A, Witte OW, Freund H (1998) Handedness and asymmetry of hand representation in human motor cortex. J Neurophysiol 79 (4):2149-2154. doi:10.1152/jn.1998.79.4.2149

Wang S, Shi Y, Shu S, Guyenet PG, Bayliss DA (2013) Phox2b-expressing retrotrapezoid neurons are intrinsically responsive to $\mathrm{H}+$ and CO2. J Neurosci 33 (18):7756-7761. doi:10.1523/JNEUROSCI.555012.2013

Wang TC, Su YN, Lai MC (2014) PHOX2B mutation in a Taiwanese newborn with congenital central hypoventilation syndrome. Pediatr Neonatol 55 (1):68-70. doi:10.1016/j.pedneo.2012.12.003

Witelson SF, McCulloch PB (1991) Premortem and postmortem measurement to study structure with function: a human brain collection. Schizophr Bull 17 (4):583-591. doi:10.1093/schbul/17.4.583

Yu Y, Fu Y, Watson C (2014) The inferior olive of the C57BL/6J mouse: a chemoarchitectonic study. Anat Rec (Hoboken) 297 (2):289-300. doi:10.1002/ar.22866

\section{Figures}




\section{Figure 1}

The Arc in Case 158 shown on 8 sections through its rostro-caudal extent $(16 \mathrm{~mm})$. a is the most caudal. The rectangles in panels $\mathrm{b}, \mathrm{g}, \mathrm{i}, \mathrm{f}$ show the location of the higher magnification images in the panels immediately to the right $(c, h, j, l)$. a. The arrow indicates the Arc on the right, a small cell group ventral to the py. It is present on the left as well but note the left-right asymmetry in size. The section is caudal to the appearance of the IOpr. b. The Arc on a section about $2 \mathrm{~mm}$ more rostral, again the Arc is present bilaterally but asymmetrical in size. The section is about at the level shown in Plate VIII of Olszewski and Baxter (1982). The rectangle shows the location of the higher magnification image in c. c. Neuronal size and spacing in the caudal Arc. $\mathrm{d}$. The Arc on a section $4 \mathrm{~mm}$ more rostral. On both sides the neuronal group is closer to the midline than in c. e. This section is $1 \mathrm{~mm}$ more rostral than the section in $\mathrm{d}$ with the Arc neurons present ventral to the py and extending up the midline (arrow on the left). f. Section $2 \mathrm{~mm}$ more rostral showing the Arc along the midline (arrow on the left). g. Section $3 \mathrm{~mm}$ more rostral showing extensive development of the Arc along the midline on the left (arrow). The rectangle shows the location of the higher magnification image of neurons in $\mathrm{h}$. $\mathrm{h}$. Neurons appear randomly scattered and examples with round, oval, elongated and polygonal somata are all seen. I. $2 \mathrm{~mm}$ further rostral the Arc is at its largest; it is present ventromedial to the py and extends up the midline. The rectangle shows the location of the image in j. j. Again, neurons appear randomly scattered with a number of different soma shapes. $k$. Section at the level of the appearance of the pontine nuclei (pn) about $2 \mathrm{~mm}$ more rostral than i. The Arc is still present along the midline. Jj Neurons in the pn are similar in size, shape and density to those in the Arc. Scale bars: $a, b, d, e, f, g, i, k=1 \mathrm{~mm} ; \mathrm{c}, \mathrm{h}, \mathrm{j}, \mathrm{l}=100 \mu \mathrm{m}$. 


\section{Figure 2}

Variability of the size and shape of the caudal Arc; 3 cases. For each pair $(a, b ; c, d ; e, f)$ the image on the left shows a low magnification image of the Arc. The rectangles show the locations of the higher magnification images on the right. a. The caudal Arc in this case is the largest of any of the cases we examined. b. The Arc consists of scattered neurons of different soma shapes. c. The caudal Arc is again larger than in Case 158 but is restricted to ventral to the py. $d$. The neurons are again randomly 
distributed. e. The section is at about the level of Plate VIII in Olszewski and Baxter (1982). The Arc in this case is similar in size to the Arc shown in Case 158 (Fig. 1B). F. Scattered neurons of different soma shapes. Scale bars: $a, c, e=500 \mu m ; b, d, f=100 \mu m$.

\section{Figure 3}

Variability of the rostral Arc in three cases. For each pair the image on the left shows a low magnification of the Arc. The rectangles show the locations of the higher magnification images on the right. a. In this 
case, the Arc is well-developed ventral to the py (arrowhead on left) but the midline cell groups are narrow (arrow on the right). b. Randomly scattered neurons with polygonal and elongated somata. c. In this case the there is a small band of neurons ventromedial to the py on the right, the band on the left is bigger (arrowhead). The midline Arc neurons Arc are a broader band than in A (arrow). C. Somata are similar to those in B. E. In this case there are almost no cells ventro-medial to the py (arrowhead) and the midline group is asymmetrical but large (arrow). $F$. The density and shapes of somata are similar to the other cases. Scale bars: $A, C, E=500 \mu m ; B, D, F=50 \mu m$.

\section{Figure 4}

Neurons in the Arc express calretinin (CR). a. Nissl-stained section showing neurons in the rostral midline Arc. b. An adjacent section showing CR-ir neurons and processes in the Arc. The arrow indicates CR-ir neurons in the IOpr. c. The rostral midline Arc in a Nissl-stained section of another case. This section is $\mathrm{mm}$ rostral to the section in Fig. 2e. d. Again, the neurons and processes of the Arc express CR. Scale bars: $a-d=500 \mu \mathrm{m}$. 


\section{Figure 5}

nNOS immunoreactivity in the Arc. a. Nissl-stained section from Case 158; the section is about $1 \mathrm{~mm}$ caudal to the section shown in Figure 1g. The Arc extends into the py (arrow). B. nNOS-ir section about 1 $\mathrm{mm}$ caudal to the section in a. The Arc is darkly immunostained; both somata and puncta are immunolabeled. c nNOS immunolabeled section from the rostral Arc showing extensive immunolabeled strands in the py (arrows). Note also the immunolabel of the IOpr ribbon. The rectangle shows the location of the higher magnification image in $\mathrm{d}$. $\mathrm{d}$. The arrow indicates an immunolabeled neuron embedded in labeled puncta. Scale bars: $a, b, c,=500 \mu \mathrm{m} ; \mathrm{d}=50 \mu \mathrm{m}$. 


\section{Figure 6}

Nonphosphorylated neurofilament protein (NPNFP) expression in the Arc. a. NPNFP immunostaining defines rArc. The rectangle shows the location of the image in b. Immunolabeled neurons (arrows) embedded in a meshwork of immunostained processes. c. Extensive immunolabel of the rArc showing invasion of the py. This section is about $.5 \mathrm{~mm}$ caudal to the Nissl section shown in Fig. 1I. Scale bars a, $c=500 \mu \mathrm{m} ; \mathrm{b}, \mathrm{d}=50 \mu \mathrm{m}$. 


\section{Figure 7}

Calbindin (CB) expression in the Arc is found in puncta not somata. a. Nissl-stained section in rostral Arc. b. Adjacent section immunostained for CB. The Arc is immunostained but somata are not apparent. The rectangle shows the location of the higher magnification image in c. c. Uneven immunostaining of puncta with darker (arrow) and lighter regions. Somata are not immunostained. d. Nissl-stained section of rArc from another case. e. Adjacent section immunostained for CB; the entire Arc shows immunolabel. The rectangle shows the location of the image in $f$. $f$. Uneven immunostaining of puncta with darker (arrow) and lighter regions. Somata are not immunostained. Scale bars: $a, b, d, e=500 \mu \mathrm{m} ; c, f=50 \mu \mathrm{m}$. 


\section{Figure 8}

Parvalbumin is not expressed in neurons or processes in the Arc. a. Arc in a Nissl-stained section; this section was shown at lower magnification in Fig. 1e. b. PV immunoreactivity on a section about $400 \mu \mathrm{m}$ more caudal. Note the very sparse immunostaining in the Arc with scattered immunostained fibers in the adjacent py. c. The Arc in a Nissl stained section from another case. d. Lack of PV-immunostaining in the Arc on a section about $200 \mu \mathrm{m}$ more rostral. Again, there are PV-ir fibers in the py. Scale bars: $a, b, c, d=$ $250 \mu \mathrm{m}$. 


\section{Figure 9}

GABAergic activity in the Arc. For each pair of images, the rectangle on the left indicates the position of the image on the right. a. Immunostaining for GAD in the midline Arc. The section is about $.5 \mathrm{~mm}$ rostral to the section shown in Fig. 3c. b. Unevenly distributed puncta. c. Immunostaining shows GABA A receptors in the midline Arc. The section is about $1 \mathrm{~mm}$ caudal to the section in Fig. 1g. d. Puncta surrounding neurons (arrow) and along processes (arrowhead). e. Immunostaining for GABA B receptors 
shows labeled neurons in rostral Arc. f. There is punctate label surrounding somata (arrow). Scale bars: a $=500 \mu \mathrm{m}, \mathrm{c}=200 \mu \mathrm{m} ; \mathrm{e}=250 \mu \mathrm{m} ; \mathrm{b}, \mathrm{d}, \mathrm{f}=50 \mu \mathrm{m}$. 